\title{
A copyright overview
}

\section{Charles Oppenheim}

How to cite this article:

Oppenheim, Charles (2020). “A copyright overview”. El profesional de la información, v. 29, n. 1, e290106.

https://doi.org/10.3145/epi.2020.ene.06

Manuscript received on $10^{\text {th }}$ october 2019 Accepted on $5^{\text {th }}$ november 2019

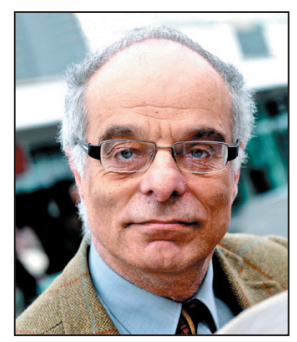

Charles Oppenheim $\triangle$

https://orcid.org/0000-0001-8195-3572

Robert Gordon University

Aberdeen, UK

c.oppenheim@rgu.ac.uk

\begin{abstract}
Review of the main concepts about copyright. Among the topics discussed are: ownership, joint ownership, assignments, licenses, permissions, infringements, exceptions, unpublished works, orphan works, artificial intelligence generated work rights, patents, trade marks, performers rights, moral rights, Sci-Hub, risk management and calculation, etc.
\end{abstract}

\section{Keywords}

Copyright; Exceptions to copyright; Infringements; Sci-Hub; Licenses; Orphan works; Databases; Moral rights; Al-created works.

\section{Introduction}

Copyright has influence on everything scholars and library and information practitioners do, including developing and giving talks, and writing or using articles, reports, books and other materials, including those in digital form. It also has an impact on those that serve the scholarly community, such as funders and publishers. This article covers the basics of copyright law from a UK perspective (other countries' laws are similar, but not identical), and other intellectual property rights of relevance before examining a few examples of how the law impacts some stakeholders. There is no easy textbook on copyright and related rights. However, a free of charge user-friendly introduction including text, video and other teaching aids has been produced by copyrightuser.org:

https://www.copyrightuser.org

An approachable official overview of UK copyright basics can be found at:

https://www.gov.uk/topic/intellectual-property/copyright

whilst similar information about local copyright laws can be found at the web sites of many other national copyright offices. Rights Direct has produced a good summary of copyright principles throughout the world:

https://www.rightsdirect.com/international-copyright-basics

\section{What is copyright?}

Copyright is an automatic right, which is created as soon as anyone makes something that is new -in other words, that has not been directly copied from something else, or represents only a minor change to something else ${ }^{1}$. Some countries require a form of registration, e.g., deposit of a copy of a literary work in a national library. The USA is unusual in that it requires registration of copyright with the Copyright Office before one can start litigation over infringement of works or the award of damages for such infringements. This requirement seems to contradict the internationally agreed Berne Convention on copyright, which requires no formalities at all, but does not seem to have been challenged. A brief description of the registration requirement and its value can be found at:

https://en.wikipedia.org/wiki/Copyright_law_of_the_United_States\#Registration_procedure

whilst Dukes and Killen (1994) have written an introduction to US copyright law. 
Copyright can apply to a wide range of artefacts, but of particular relevance to scholars are words (as in this article or in a book, and sometimes called "literary works", though there is no requirement for literary merit), numbers (as in research data), images such as photographs, paintings and drawings, (also known as "artistic works", though, again, there is no requirement that they must have artistic merit.) Another category is moving images (as in, for example, a film or video). There is also protection for sound recordings, for dramatic works (such as the text of a play) and for musical works. At the moment, copyright only protects products of the human mind, whether created in a few seconds or the result of years of effort. There is no copyright in things produced by nature, or by other living organisms. There is a question regarding things produced by computers; arguably purely computer-generated outputs where there has been no human input apart from the original programming effort (where there would be copyright in the software) do not enjoy copyright, but this is an area where novel copyright concepts might emerge in the future. I discuss copyright and artificial intelligence later in this article.

Countries differ somewhat on what outputs of the human mind might be protected by copyright. Some countries classify copyright works into formal headings, e.g., literary works, artistic works, sound recordings as listed above, whilst others simply demand protection for works of the human mind, without classifying them. All countries require, whether explicitly or implicitly in their laws, that the protectable subject matter must be fixed in some way, though they might not specify a minimum length of time for fixation or the medium on which the fixation occurs. Some countries' laws further require that the creator (or someone authorised by the creator) must carry out the fixation. Indeed, sometimes if an unauthorised person carries out the fixation (say they tape record a live music performance contrary to the performers' wishes), they have indeed created a copyright work, but in doing so they will have infringed the performers' rights. If two people totally independently create something identical (say a poem), then both authors will independently own copyright in the work.

\section{Creativity}

To enjoy copyright, the item created must involve a minimum of creativity. Thus, a simple photograph of (say) a statue will not enjoy copyright, but if the photographer used skill and judgement on lighting, exposure time, etc., then it will enjoy copyright. As the well-known Infopaq case (decided by the European Court of Justice) confirmed, even a sentence comprising 11 words can enjoy copyright ${ }^{2}$. Rosati has provided background on Infopaq and its implications (Rosati, 2011).

\section{The () sign}

In general, there is no requirement to put a copyright notice or a "(C) attached to the artefact, though it is often useful to do so to flag up a warning to third parties.

\section{Lifetime}

In most countries in the world, the lifetime of copyright for published works is often (but not invariably) 70 years after the end of the year when the creator died. Wikipedia has created a list of lifetimes in countries:

https://en.wikipedia.org/wiki/List_of_countries\%27_copyright_lengths

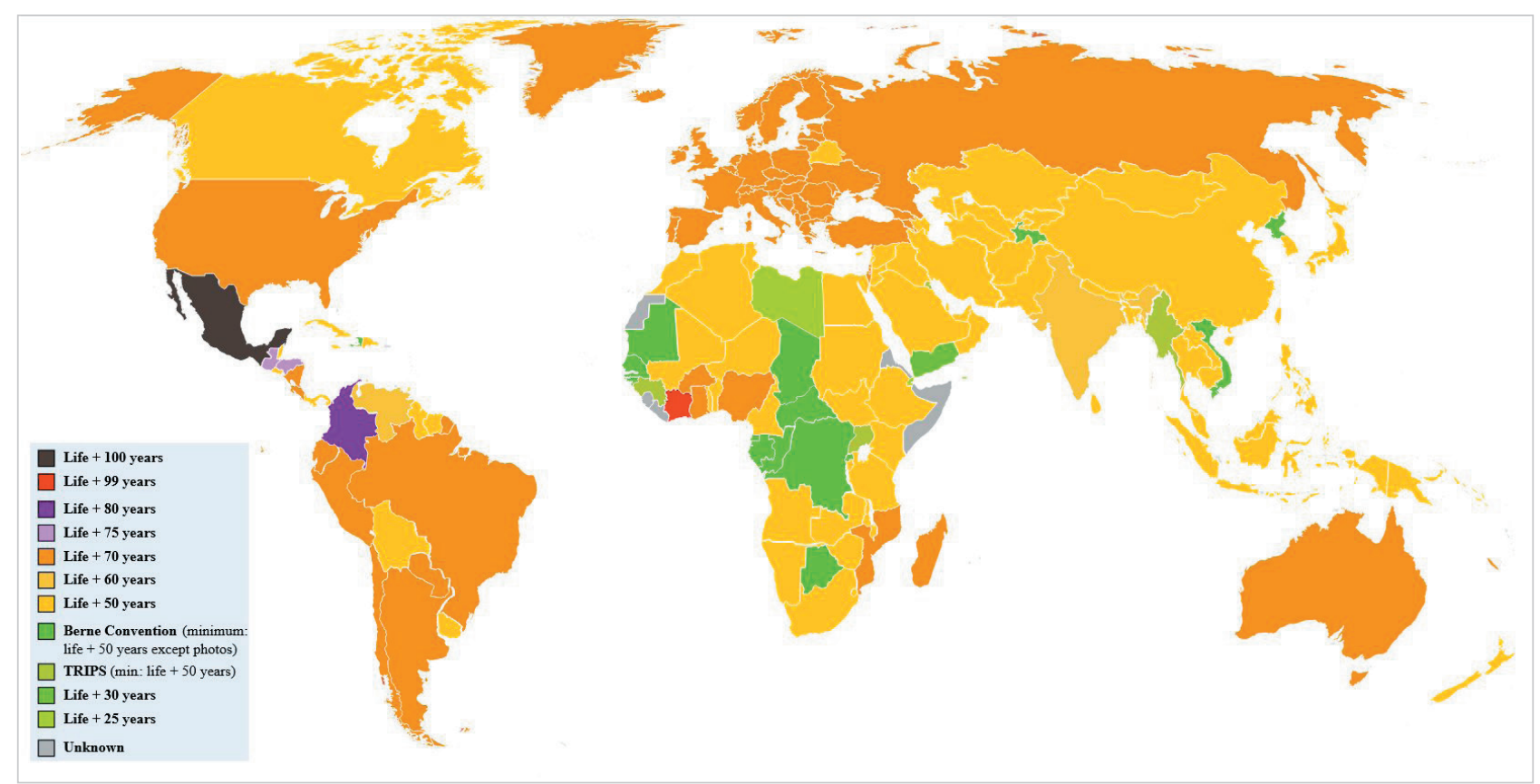

https://commons.wikimedia.org/w/index.php?curid=20388347 
but one should not rely $100 \%$ on the list, as it simplifies what are often complex rules, and ignores some classes of protected creations. Unfortunately, there are numerous special cases, and the nature of what makes it a special case and the resulting lifetime varies from country to country. These are not considered further here, but just as examples, there are special rules for jointly created works, for anonymous or pseudonymous works, and for works that are "unpublished". "Unpublished" refers to works that have not been available to the public or a significant sub-set of the public, whether for free or for a fee. The copyright lifetime for unpublished works can be exceptionally long. Unpublished works include letters, preliminary artwork, unpublished data, many photographs and much else. To give an example, unpublished works (whether the author is known or unknown) are protected in the UK by copyright until the end of 2039 , no matter when they were first created ${ }^{3}$. Thus, even a $14^{\text {th }}$ century private letter will still be in copyright in the UK (and in some other countries). By contrast, published works include a large proportion of the material a scholar typically encounters, or creates, on a daily basis. There are also special rules for so-called "orphan works", i.e., works that are in copyright but no one can trace who the owner is. Orphan works are discussed further below.

\section{Similarity among copyright laws}

Although copyright laws have different origins depending on the country and its particular legal traditions, whether with a civil law tradition or a common law tradition, in practice, copyright laws in every country in the world are very similar. It is for this reason that international copyright agreements are widely accepted. For example, virtually all the countries of the world are signed up to an international convention (the Berne Convention) that sets ground rules for national copyright laws. It sets the minimum term at life plus 50 years, but many countries have made the lifetime of copyright in their country longer, such as the life +70 years noted above. One important aspect of the Conven-

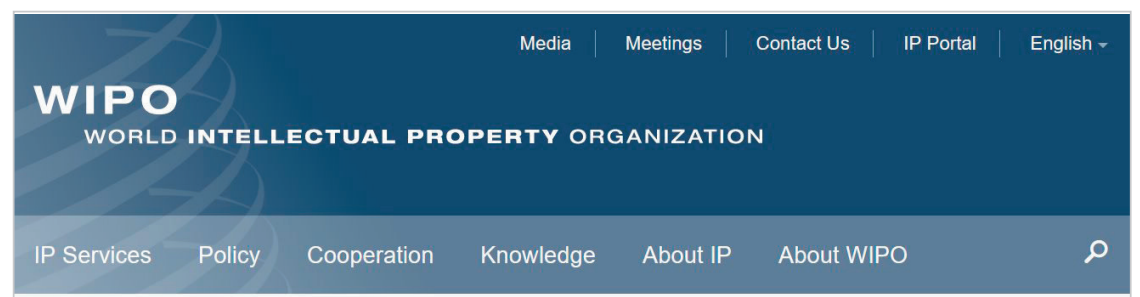

Home, Knowledge, WIPO-Administered Treaties

\section{Summary of the Berne Convention for the Protection of Literary and Artistic Works (1886)}

https://www.wipo.int/treaties/en/ip/berne/summary_berne.html tion is that copyright created in one country automatically gets protection in every other country. Thus, something created in, say, Japan, automatically has protection in the UK, and vice versa. More background on the Convention can be found $\mathrm{at}^{2}$ : https://en.wikipedia.org/wiki/Berne_Convention

Seville (2006) has written a readable account of the history of the development of international conventions in copyright.

Once the creator dies, any copyright they owned passes to their heirs and successors; ownership is discussed further below.

\section{Ideas can't be copyrighted}

Copyright does not protect ideas that have not been recorded in some way, or simple facts - more on the latter below. The former concept is known as "the idea/expression dichotomy," which embodies the proposition that copyright extends only to the expression of ideas in a work, not to the ideas themselves (Dukes; Killen, 1994, pp. 28, 30).

\section{Restricted acts}

The most important right that comes with copyright is the right to do, or authorise others to do, so-called "restricted acts". These acts include:

- copying the work (the so-called "reproduction right"),

- issuing copies to the public (the so-called "distribution right"),

- communication to the public by electronic or other means,

- renting or lending the work,

- performing the work (performers rights are considered below) and

- adapting the work (the so-called "adaptation" or "derivative works right").

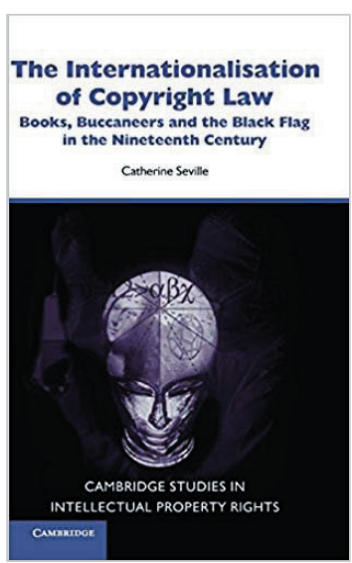

ISBN: 9780511495274

These rights end when copyright in the work expires, and the work is then said to fall into the public domain, and anyone can do what he or she like with it. How one defines "the public" in these various rights varies from country to country. 


\section{Object ownership $\neq$ copyright ownership}

Perhaps the most important point to make is: just because you own a physical object (or have access to it in some electronic form) does not mean you own the copyright in it, and so, you are not necessarily free to do things such as reproducing it without express permission. Thus, just because an individual owns a copyright work (say a painting), does not mean they can (say) create and sell postcards or images of that work. All they are entitled to do is sell or give away the item they own, if they so wish, and/or display the item. This rule, first established in the Pope $v$ Curll case in England in 1741, is accepted worldwide (Brennan, 2015). Curiously, it seems that Pope deliberately conspired with Curll to have the latter publish a "pirated" edition of Pope's own writings to establish this legal precedent! (Feather, 1994).

Just because you own a physical object (or have access to it in some electronic form) does not mean you own the copyright in it

Copyright applies to electronic materials in the same way as it does to more traditional materials. Thus, materials on the Internet are subject to the same rules as, say, printed or hand-written materials.

\section{Ownership}

The first owner of the copyright in a creation is normally the creator. However, if an employee creates the work in the normal course of their employee duties, or if a third party has specially commissioned the work, then in many countries (but not all), copyright in what is created automatically belongs to the employer or whoever commissioned the work. Some countries have special rules for jointly authored software, or audiovisual outputs where the numbers of people involved in the creation may be in the hundreds.

Copyright in something created by a scholar at home in the evenings or weekends will still belong to their employer if the creation was part of the employee's expected duties. Equally, copyright in something created by an employee during work time and using their employer's resources, but is nothing to do with their expected duties belongs to the employee. Of course, the employer would be perfectly entitled to dismiss the employee for not doing their employee duties, but the copyright would still stay with the individual. This raises interesting questions regarding what an employee can take away with them when they change jobs, or end their employment. Are they entitled to make copies of, or remove the originals of, materials they created whilst in the earlier employment? Strictly speaking, the answer is "no", but some employers might turn a blind eye to what copyright materials that they created an ex-employee takes away. Copyright in text written by an author for a publisher is discussed further below. Any employee-created materials ceases to enjoy copyright if more

Copyright in something created by a scholar at home in the evenings or weekends will still belong to their employer if the creation was part of the employee's expected duties

than the standard rule years for copyright in the country it was created have passed since the employee died. Joint authorship rules vary from country to country, as do the rules regarding what one author of a jointly created work can do in terms of granting permission to third parties to copy the work.

\section{Assignments and licences}

Whoever owns the copyright in a creation is entitled to either pass the ownership over to a third party (assignment) perhaps for money, or to give permission to third parties to do some or all the possible restricted acts, again perhaps for money (licensing) if they so wish. It is worth noting that a licence can be an explicit written agreement, or can be implied from custom and practice. In contrast, an assignment has to be in writing. Such agreements, whether a licence or an assignment, often happen when an individual writes an article for a journal, or writes a chapter for, or writes an entire book. If a book contains an index that has been created by someone else (such as a professional indexer), the copyright in that index belongs to the person who created the index in the first instance, but typically will be assigned or licensed to the publisher or author for a fee. Incidentally, if an index (or indeed any other creation) has been created with the help of software, it is not the software creator who owns the copyright, but the person who programmed it.

In some cases, a licence can be implied by the actions (or lack of actions) by a copyright owner in response to re-use of their materials. It is always best, however, to have a formal contract signed by the interested parties in place. Reproduction of materials in an article, report or monograph (whether in print or electronic) may well involve using third party materials with perhaps multiple copyright owners. A person wishing to reproduce such materials might have to approach several different parties for permission to do so. It is worth noting that sending a copyright owner a message along the lines of "unless I hear to the contrary I shall assume you have no objections to me reproducing the item" has no legal validity.

Where there is joint ownership, such as with a jointly authored article or book, then each party has rights and responsibilities, which, in turn can sometimes mean one of the owners, cannot do things with the work without the permission 
of the other owner(s). This is a complex legal area and is not discussed further in this article except to stress that for jointly authored materials, ideally, all the authors should come to an agreement at the outset regarding copyright ownership of their creations.

\section{Infringement and exceptions to copyright}

If a third party does any of the restricted acts to all, or a "substantial part" (see below) of another person's work, without permission, that third party may well have infringed the copyright of the work. The copyright owner can then sue the infringer for damages, representing the financial loss for the copyright owner or the financial gain for the infringer, plus of course legal costs. In more severe or blatant cases, there may be criminal sanctions as well, such as fines or even prison. What is considered "substantial"? There is no fixed rule. Each case would be considered on its own merits; court cases have looked not at the proportion of the original that has been copied, but its importance. As noted earlier, the European Infopaq case deemed 11 words from a text was "substantial", and an earlier UK case decided one single frame from a film was substantial. With this, as with so many things in copyright, one has to make a judgement call.

The development of new ways to disseminate information by electronic means has led to new legal concepts to handle infringements caused in this way. Thus, many countries have introduced laws that give legal backing to so-called "Technical Protection Measures", or TPMs. These are software or hardware systems developed for use by rights owners to prevent unauthorised access to, or dissemination of, copyright materials. The laws that have been developed make it an offence to by-pass or disable such measures with the intention of infringement. The problem with such laws is that they may well prevent a person carrying out bona fide activities, such as something permitted under an exception to copyright (see below). National governments have responded differently to this problem, which seems to me to not be capable of easy resolution.

\begin{abstract}
It is worth noting that sending a copyright owner a message along the lines of "unless I hear to the contrary I shall assume you have no objections to me reproducing the item" has no legal validity
\end{abstract}

\section{Exceptions}

For good public policy reasons, the law allows certain activities that would otherwise be infringement to be done without having to ask for permission or having to pay any fees. These are known as exceptions to copyright. One should distinguish exceptions, which allow someone to do something that would otherwise be infringement because of the wording of the law, and limitations, which allow a person to do the infringing act but require payment at levels usually set by Government -in effect, compulsory licences. The discussion here focuses on exceptions. Under an exception, anyone can copy all, or a substantial part of a work, as long as it is for a permitted purpose (as specified in the local legislation) and as long as the copying does not damage the legitimate interests of the copyright owner. The three major permitted purposes in most countries (countries are not consistent in the way they have built exceptions into their laws) are:

- non-commercial research or private study;

- quotation of a small part; and

- criticism or review.

Many countries also include in their copyright law an exception for non-commercial educational purposes, and some have introduced, or are planning to introduce, one for text and data mining for non-commercial purposes. Text and data mining (TDM) involve the use of software to scan through large volumes of text or data in order to identify and extract trends in the use of particular words or data. It has widespread potential uses, but is currently hampered by the fact that in many countries, the initial downloading and/ storing of large volumes of text or data is potentially copyright infringement, even when the purpose of the mining is non-commercial. Horvath (2019) has written a short readable article on the background to a proposed EU-wide copyright exception to TDM.

A brief overview of the rationale behind exceptions can be found in a Wikipedia entry:

https://en.wikipedia.org/wiki/Limitations_and_exceptions_ to_copyright

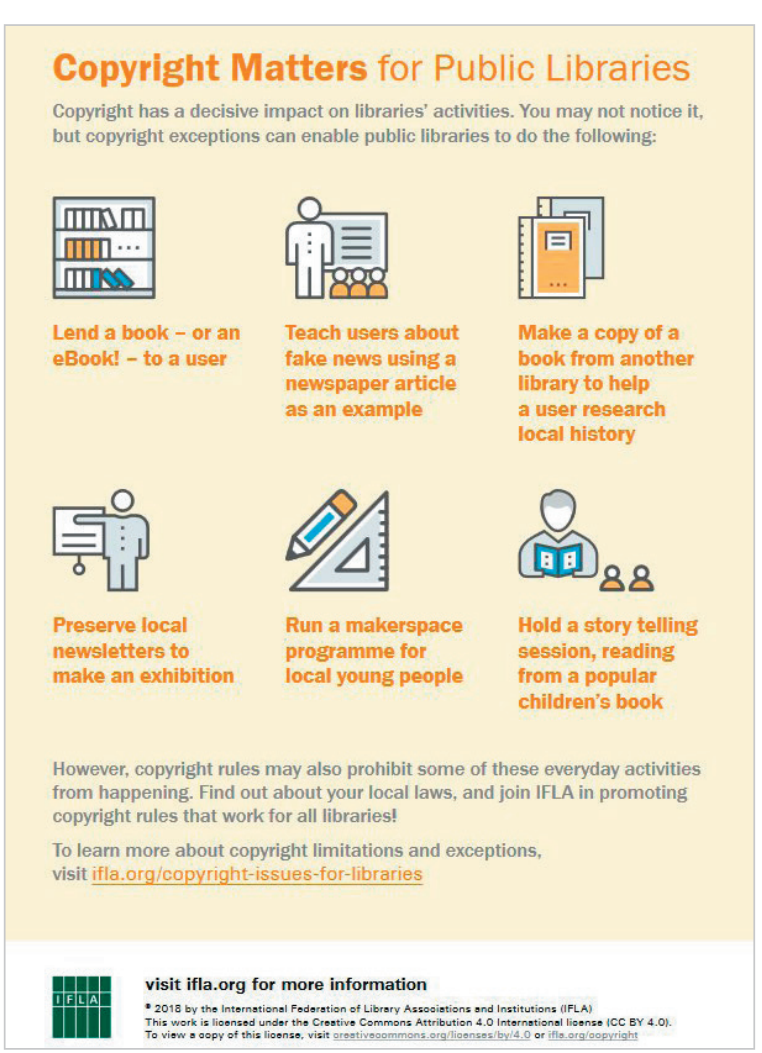

https://www.ifla.org/copyright-issues-for-libraries 
"Non-commercial" as a term used in copyright laws can cause a problem regarding its definition. It is normally understood along the lines of the intention of the activity is to create something that makes money, for example a priced monograph (where, in addition to the publisher earning income, the author may also earn royalties from sales). But there are many circumstances where the intention is not to make money, but perhaps to save expense, or where any money generated is incidental to the initial reason for carrying out the activity. Most, but not all media types are covered by exceptions to copyright. Quotation can be for any purpose, but what is being quoted should be relevant to whatever the argument the user of a quotation is making. Note that copying an item for criticism or review does not have to be criticising the item copied, and in any case "criticism and review" are terms that are interpreted generously.

In addition, libraries and archives typically have an exception allowing them to make copies of items for bona fide researchers, and even to charge for such a service if they so wish (not all libraries choose to levy charges for providing copies). It is likely that many readers of this article will have taken advantage of this or indeed may well offer such a service. Such library exceptions are typically restricted to the making of a single copy (printed or a photocopy) for any given patron. The law typically does not usually allow such copies to be in digital form, or to be delivered by electronic means, unless the scanning and delivery of the scan is to a single terminal, where it is then printed out for the library patron, and so long as the scan is then immediately deleted. If a library wishes to offer a service to provide copies of its holdings to patrons in digital form, including on multiple terminals to patrons on demand, typically it will have to obtain (and pay for) licences from publishers or other distributors.

In all cases of relying on exceptions, the person being sued (or threatened) for infringement would have to demonstrate that the copying was indeed done for one of the permitted purposes and did not damage the legitimate interests of the rights holder. Thus, an exception to copyright is a defence to be used if one is sued for infringement, or is threatened with legal action by the copyright owner, but is definitely not a guarantee of immunity.

Merely displaying a copyright item in, say, a presentation is not infringement as long as it is the original, and not a copy that is being shown. Showing a copy of a copyright work in a talk is also probably acceptable, as the action is likely to fall under one of the exceptions to copyright.

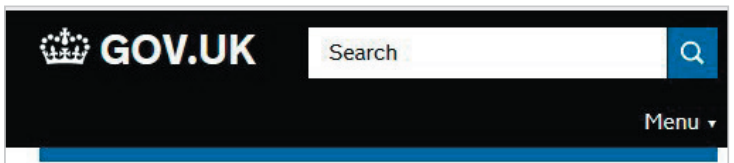

$\underline{\text { Home }}>\underline{\text { Intellectual property }}>\underline{\text { Copyright }}$

\section{Guidance}

\section{Copyright: orphan works}

How to get permission to copy a creative work for which the right holder(s) cannot be found ie an orphan work.

Published 12 May 2015

Last updated 4 December 2019 - see all updates

From: Intellectual Property Office

https://www.gov.uk/guidance/copyright-orphan-works

\section{A particular problem: orphan works}

Researchers in some disciplines, including, but not limited to, history and politics are more likely to encounter older works that are still in copyright than those in the hard sciences. This is either because it is less than 70 years since the creator died, or because the works in question are unpublished, such as letters and private reports, which, as was noted above, can have a surprisingly long copyright lifetime. Many of these will be so-called orphan works. Orphan works are works that are still in copyright, but where it is impossible to identify or track down the copyright owner, and so there is no one who can be identified to approach when seeking permission to carry out a restricted acts on that work. The problem applies to all media, including photographs, films, broadcasts and textual materials. However, all is not lost. They may well be justified in copying and reproducing the items under one of the exceptions to copyright noted above; the risk equation towards the end of this article may also be of assistance in such cases. Some countries, including EU member states, have special permissions and licensing schemes available -see, for example:

https://www.gov.uk/guidance/copyright-orphan-works

Useful background about the EU's initiatives can be found at: https://en.wikipedia.org/wiki/Orphan_Works_Directive

However, it must be said that these schemes may not suit every user's needs.

\section{Other intellectual property rights of relevance}

Copyright is one of a collection of different legal rights that are collectively known as Intellectual Property Rights. Many of these are of limited or no relevance to scholars or information professionals, but are certainly potentially relevant to those involved in the history of, or are working on current developments in, a technology. 


\section{Patents}

The first of these are patents. As a rule, copies of patents can be made for a talk, display or publication. Patent law requires that one should apply for a patent if one has made a worthwhile invention before publishing anything about it. If a so-called prior publication, such as a journal article describing the invention, has been published before the date a patent is applied for, then no patent for the invention will be granted. This is a complex, but important area of law, and anyone who encounters, or is likely to encounter, such patents for inventions should take specialist advice. There are, for example, specialist societies for the patent searching community, such as the Patent and Trade Mark Group of the Chartered Institute of Library and Information Professionals (Cilip) in the UK.

\author{
Under an exception, anyone can copy all, \\ or a substantial part of a work, as long as \\ it is for a permitted purpose
}

\section{Registered trade marks}

Registered trade marks can also be important. These prevent unauthorised use of a registered name or logo (or anything confusingly similar to it) by third parties promoting similar goods or services. It would not usually be an infringement of a trade mark to reproduce it in a publication unless the article published is promoting a product or service whose trade mark is confusingly similar or identical to a registered trade mark for the same class of goods or services. Registered trade marks are registered in individual countries (there is an EU-wide mark as well). Again, there is useful background in Wikipedia:

https://en.wikipedia.org/wiki/European_Union_trade_mark

and when applying for such a mark one must specify the classes of goods and services the applicant wishes to have protection for. The lifetime of all trade marks is potentially infinite.

\section{Performers rights}

Performers rights are also important for anyone who gives talks, presentations or does acting, singing or playing musical instruments, or makes use of audiovisual materials containing such performances. This gives the presenter (who is automatically the owner in the absence of any agreement to the contrary) the right to prevent unauthorised recording of and/or dissemination of their performance.

\section{Moral rights}

Moral rights, which are not applicable in all countries, give a creator the right to be identified as the creator, and the right to object to derogatory treatment of their work, such as amending it in such a way that it damages the reputation of the creator. The lifetime of moral rights is generally the same as for copyright.

\section{Database rights}

Arguably, the most important right other than copyright for those involved in the creation and use of materials that LIS professionals handle is, however, database right. There is no copyright in a fact ("the Second World War lasted from 1939 to $\left.1945^{\prime \prime}\right)$, but there can be protection, in the form of copyright and/or database right, for a collection of facts or of copyright works. Such a collection of items gets copyright if it is original by reason of the selection or arrangement of the materials within it, even if the selection and arrangement is minimally creative. Gaining protection for such a collection does not affect the copyright status of the items within the collection; depending on the amount of creativity involved in the original items, the age of the individual items, etc., each item may or may not separately enjoy copyright. A listing of (say), all breeds of dogs might well enjoy copyright because the creator has used their skill and judgement to decide if a particular dog is a separate breed, or is not. The author of a restaurant guide that awards points for food quality, value for money, etc., will have copyright in the collection of scores awarded, but cannot stop third parties from reproducing details, such as name, address, phone number or URL of the restaurants themselves. Those are individual facts that do not have any protection.

Any collection that involves little judgement in selection and arrangement is unlikely to enjoy copyright. However, such collections may well enjoy database right in those countries that offer it (primarily EU member states) if the creator has made a substantial investment in obtaining, verifying and presenting the contents. Database right does not last as long as copyright, and the penalties for infringement are not as harsh as for copyright infringement, but nonetheless it is a useful addition to the armoury of creators - and a hurdle to consider for users of such materials.

\section{Registered designs}

Registered designs, which protect the aesthetics of physical objects, are not considered further here, except to note that in some countries such objects are also protected by copyright. Preparatory artwork for such designs is usually considered artistic works under copyright law. 


\section{Implications for some specific stakeholders}

Many libraries have explicit permission in law to make copies of items (typically in the form of photocopies or printouts) in their collections and to supply said copies to requestors under exceptions to copyright. The patron may have to fill out a form before they can get the copy. One problem that might arise is if a requestor needs a copy of an item for their commercial (as opposed to non-commercial) research.

Authors of books and articles must ensure that what they write is either not copied from a third party-owned source, or that they have permission to copy such third party text or images they reproduce-assuming, of course, that such copied material is still in copyright. Alternatively, if using third party material, one or more of the exceptions to copyright might cover the authors.

Book, journal, conference and magazine publishers should ensure that everything they publish is clear of potential copyright problems. They therefore will often require authors submitting material for publication to provide a warranty that confirms that nothing the author has supplied will infringe copyright (or any other law, such as data protection, defamation, and official secrets) and that the author indemnifies the publishers against all costs should it turn out that the warranty is mistaken. They may or may not quite separately require the author to assign copyright in the work to them, or may be content simply with a licence to reproduce, with the author retaining their rights; it would be a mistake to rely on implied licences for a monograph, but implied licences are not uncommon in magazine publishing. If the publisher amends the work in any way before publishing, they risk infringing the moral rights of the author (unless the author has agreed to waive their moral rights, something that is possible in some countries), and so should check that the author is happy with the amendments. Moral rights only kick in if the amendments damage the author's reputation, so very minor changes are very unlikely to cause concern. It is probably safe to assume that the author of a piece in a magazine owns the copyright in the work (unless it was written by an employee as part of their employee duties) and that the author, by submitting the article to a magazine publisher, has granted the publisher a licence (whether in writing or implied) to reproduce the item.

In addition to the various copyright issues raised by talks, another needs to be considered if the talk is live streamed or video recorded_and that recording is then made available online, e.g., on YouTube. The person giving the talk has performers rights in their performance (for that is what it is), and so has the right to control the reproduction of that performance. This means that explicit permission to record must be sought from the person giving the talk in advance of the event. If the screening or recording shows any members of the audience, then they should be asked to sign a statement that they agree to be so included, to avoid any data protection problems that, however unlikely, might arise.

Any organisation that scans or otherwise copies materials for preservation purposes will probably be able to do so because of relevant copyright exceptions, but putting the resulting scans on, say, a web site or forwarding the scans in machine readable form to a third party might be problematic.

If something is posted on the web, it can get widely copied and disseminated. Caution is required if reproducing something taken from the web. In particular, one should check if the material is available under a Creative Commons licence (such as everything on Wikipedia is). This says, in effect, "I retain the copyright, but feel free to reproduce this at no charge." There are several types of Creative Commons licence and you should be careful to follow the rules associated with anything you use which is under such a licence. A user may not have permission to amend the item, or make money from it, depending on the particular Creative Commons licence involved. The rules are explained at the Creative Commons web site.

https://creativecommons.org/share-your-work

It is worth noting that the Internet has brought other players into the copyright arena, i.e., intermediaries such as search engines, hosting platforms and link aggregators. Their activities raise questions of their possible liability for acts of copyright infringement that take place by persons using their systems. Such intermediaries might not be directly engaging in copyright infringement, but may be seen to be facilitating it. In the USA and EU, such services often enjoy exemptions from liability for any infringements that take place when their services are used. In contrast, a good example of exploitation of the Internet for explicit copyright infringement purposes is Sci-Hub ${ }^{4}$.

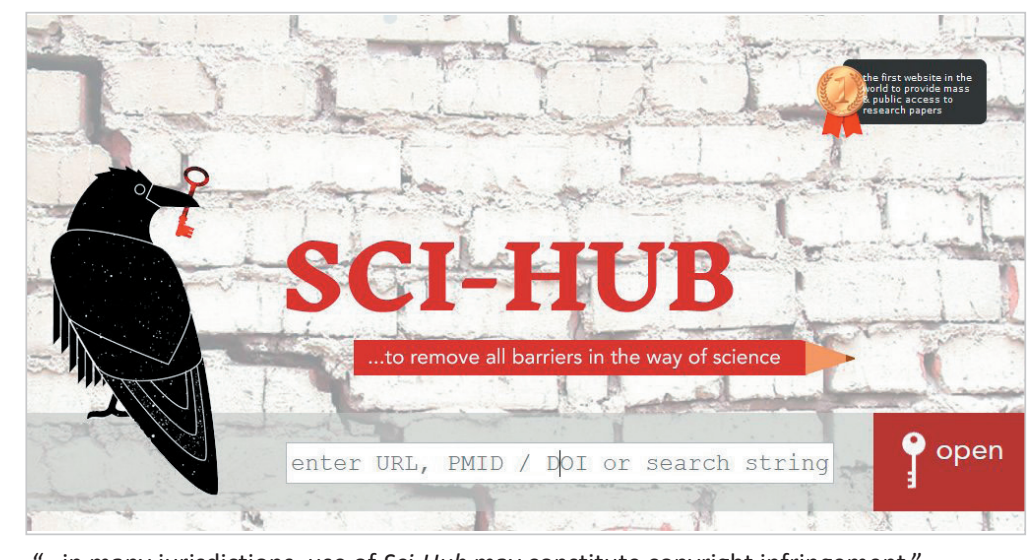

“...in many jurisdictions, use of Sci-Hub may constitute copyright infringement." 
This website provides free access to millions of research papers, deliberately infringing the copyright of the copyright owners (frequently commercial scholarly publishers), bypassing publishers' paywalls and technical protection measures. Sci-Hub was founded in 2011 in response to the high cost of research papers behind paywalls. The site is widely used around the world, serving hundreds of thousands requests per day. It seems that a significant proportion of its usage is by individuals who work for organisations that have the relevant subscriptions to publications, i.e., they can get direct access to the materials without hitting any paywall or technical protection barrier. This might be because Sci-Hub's search systems are better than those offered by bona fide publishers or distributors, or because the individual doing the searching uses Sci-Hub so often they have come to rely on it as their primary source of information. Sci-Hub has been sued for its blatant copyright infringement, and has lost these cases, but the publishers who sued have not received any compensation; they have, however, forced Sci-Hub to change its URL addresses, but this outcome does not seem to have caused Sci-Hub any problems. Himmelstein et al. (2018) provide useful background on Sci-Hub, its growth and usage. They rightly stress

"it retrieves and distributes scholarly literature without regard to copyright. Readers should note that, in many jurisdictions, use of Sci-Hub may constitute copyright infringement. Users of Sci-Hub do so at their own risk".

\section{When is it OK to copy?}

- If the work is so old that it is out of copyright. It is reasonable to assume that anything that has been published and is more than 125 years will be out of copyright. But a recent edition of an old work may still be in copyright if the creator of the new edition has added notes or commentary. However, unpublished materials may well be still in copyright no matter how old they are, as noted above. These should not be copied without consideration of risk management, as discussed below.

- If the amount copied is so small to be considered "insubstantial", but note "substantial" is measured in terms of both length and importance of what is copied, so care is needed.

- If the copyright owner has granted permission. This may be because the user has obtained a licence to use the materials (perhaps by asking the copyright owner directly), or because the copyright owner has granted a free of charge licence, such a Creative Commons, to all.

- Where the copying is under an exception to copyright, such as for non-commercial research or private study. This will not apply if the purpose is for financial gain, for example to earn royalties, but would apply when the purpose is clearly non-commercial.

- There may be an implied licence permitting copying of what can be found on the web, but readers should not assume that just because it is on a web site that it is acceptable to copy the materials. Check the terms and conditions of the web site (if any) and whether it is reasonable to assume the copyright owner (who may not be the same as the organisation running the website) would grant permission to copy.

- Many government-issued outputs, including Acts of Parliament, official advice notes, patent specifications, and some other materials produced by Governments, as well as reports of legal cases in many countries, can be freely copied.

\section{Two current copyright issues}

\subsection{Technological challenges}

\section{Text and data mining}

One of the most interesting issues in copyright is how it responds to new technological challenges. I have already noted that the ability to undertake large scale text and data mining has led to changes in the law to protect the use of technical protection measures that restrict users' ability to download the large amounts of text and data required for such mining and subsequent analysis. This is a classic case of rights owners responding defensively against technical possibilities that challenge their traditional grip on how data and information is exploited.

\section{Artificial intelligence}

Another example of the sorts of challenges relates to the rapid improvements in artificial intelligence (AI) tools and software in recent hears, with the promise of further improvements in the near future. There is right

A key question is whether copyright exists at all in Al-created works now ongoing discussion on whether Al will change human creativity and how Al-generated works should be protected.

A key question is whether copyright exists at all in Al-created works. This is an issue considered by Burt and Davies (2018) and by Guadamuz (2017), who provides interesting background to the question of whether Al-created artefacts should enjoy copyright. The types of works produced by Al systems will have the same appearance as those created by humans. In other words, it will be impossible to distinguish between the output of the human intellect and that of Al software. National copyright laws' philosophy tend to fall in two traditions; 
- the first is that copyright is justified as it protects the products of the human mind, and

- the second is that copyright is justified to protect the skill and effort put in by a creator.

For those countries where copyright law is based upon the idea that protection can only be given to products of the human mind, Al-created works should not be protected. Although it might be possible to argue against this by saying that an author makes arbitrary choices, just as an Al-driven computer does, this argument may be incorrect, as people make, as far we know, subjective decisions whereas Al machines follow predetermined rules. But maybe at some time in the future, scholars will find evidence that humans are akin to pre-programmed computers; we just don't know enough about human thought processes yet. Looking to countries where a work receives copyright protection only when effort and investment is made, how does this apply to Al-created works? Effort and investment have gone into creating the Al software and hardware, but arguably not the work, which is generated by setting the Al system to work.

Another problem in both traditions of copyright law is that a work has to come from a

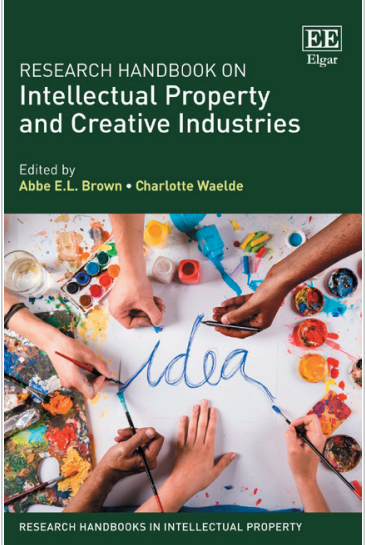

ISBN: 9781786431165 human. It might be possible argue there is a precedent in those copyright systems which automatically transfer copyright from an employee to an employer. However, there is no person creating the work, and so no one who can be the initiator of the transfer.

In conclusion, it looks like there are three options to the challenge posed to copyright law by Al. Two of them work on the assumption that we want to give protection to such Al-generated works. Either it is agreed to develop a brand new right outside traditional copyright, called, say, AIGWR (Artificial intelligence generated work right) ${ }^{5}$, or copyright law will have to fundamentally change to abolish the requirement that it is linked to a human's creativity. There are precedents for this idea; the UK has a good system to deal with Al-generated works under its current Copyright Act, whereby copyright in a computer-generated work is owned by the person by whom the arrangements necessary for the creation of the work are undertaken ${ }^{6}$ (or, of course, their employer should the work have been carried out as part of employee duties). Similar provisions also exist in a few other countries' copyright laws.

The third, and in my opinion by far the least likely option to be accepted, is that Al-generated works do not receive any protection at all. If it is decided that Al-generated creations should not have copyright, some interesting implications follow. Because machines are getting so good at creating works that they either are, or will be very soon, indistinguishable from human-created works, and if those wor-

We need to ensure artificial intelligence generated works do receive copyright

ks do not have copyright protection and therefore are in

the public domain, what will happen to human-created works? Will humans be able to compete in the creative writing, film-making, music making, or computer games marketplaces? I doubt it. That's why we need to ensure Al-generated works do receive copyright.

Lots of work will no doubt come up on this topic in the future at the World Intellectual Property Organisation (WIPO), the UN body that handles international copyright matters!

\subsection{Private vs public interest}

The second major issue in current copyright discussions is the balance between the uses of copyright to protect private (typically commercial) interests versus the public interest in access to knowledge. Much of the debate has been triggered by concerns in the scholarly publishing arena, why authors of scholarly outputs are pressurised by commercial publishers to either assign copyright, or grant an exclusive licence to commercial publishers in return for the reward, kudos and promotion/funding opportunities that result from having got an output published by a prestigious publisher. This debate has revolved around the idea of open access outputs, i.e., scholarly publications that are free for anyone to read and use, as opposed to traditional toll access outputs, which one can only get access to by either paying oneself or by being employed in the organisation where the organisation has paid sums of money to the publishers. The debate, though, is broader than just this. At a time where there is considerable concern about the future of the planet due to global warming, there is a concern that such a crisis requires an informed public to participate, and that is not possible if much of the evidence and discussion is behind paywalls. Civil society groups in both developed and developing countries argue that current copyright laws compromise the necessary access to knowledge and thereby reduce things such as basic rights to food and good health. Social movements have emerged that favour making policy-making on copyright and other forms of intellectual property appropriate to the goal of affordable appropriate access for the good of humanity as a whole. If this was not bad enough, there is plenty of evidence that even within

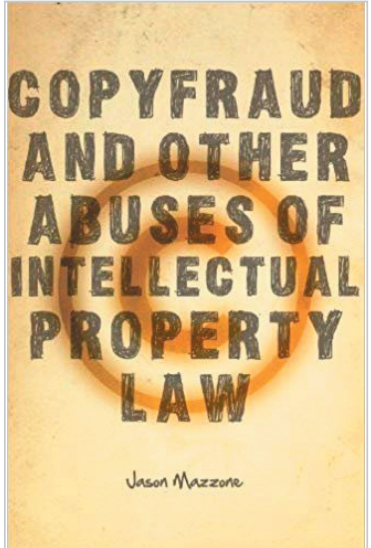

ISBN: 9780804760065 
the current law, copyright owners are abusing their powers beyond acceptable norms. Mazzone (2011) provides some examples of this sort of activity.

All of this raises a fundamental question: who should have priority in copyright? The general public or private corporate interests? The argument is that the excessive length of copyright protection combined with exploitation of other intellectual property rights (especially patents) means that the balance is currently far too heavily skewed in favour of private corporate interests. Even the term "rights" in "Intellectual Property Rights" is challenged, as these "rights" should really be known as "monopoly privileges" which damage fundamental human rights. Similarly, critics have complained about the terms "theft" or "piracy"

Who should have priority in copyright? The general public or private corporate interests?

when referring to deliberate infringements of copyright, as such terms imply that anyone who does such actions (for example Sci-Hub mentioned earlier) is automatically cast as the bad guys. One way of reducing the dominance of copyright and other intellectual property rights is the controversial idea of compulsory licences made available by laws to reduce the power of intellectual property rights. Such licences may or may not involve payment to the rights owner. The idea of compulsory licences raises the question of when, and to what extent, they should be used, and should every country in the world have compulsory licences written into their legal systems? There are already some compulsory licence provisions for translation and reproduction of copyright works in some developing countries, but such compulsory licences have rarely been used. In the past, countries that have such provisions in their laws have been very reluctant to use them for fear of antagonising the private sector, and perhaps thereby reducing investment from other countries. An alternative approach to compulsory licences is a significant expansion of exceptions to copyright, but here too one can expect vigorous opposition from vested commercial interests.

My own view is that the current copyright system is too heavily skewed in favour of copyright owners, and that rebalancing by changes to the law is required. This requires a concerted worldwide effort through WIPO. But expect the fight to be difficult; the vested corporate interests have the money and lobbying power to delay or nullify any such efforts, and WIPO's own history in these debates so far does not inspire confidence about its ability to push the agenda forward at a reasonable speed.

\section{Risk management and calculation}

Deciding what can be done with a copyright work one has not created oneself is, in my opinion, more to do with management of risk than it is to do with the statutes. What are the chances that a copyright owner will make a complaint of infringement and threaten to sue? The odds are low, but not zero and in some circumstances can be very high. Anyone using third party copyright materials has to take a risk management approach. A useful resource to help on this can be found at:

https://www.copyrightlaws.com/developing-copyright-risk-management-plan

Amongst the points it makes, the following (lightly edited by me for clarity) are particularly helpful:

"Locating a copyright owner can be a daunting and often impossible task. The Internet has made the task somewhat easier, but the problem still remains. You want to reproduce a certain work, for instance, and despite all your online searches, telephone calls, emails, faxes and snail mails, you're at a dead end-you cannot identify who owns the copyright.

In other words, you are dealing with an orphan work. You then have two choices. First, don't reproduce the work; instead, either find another copyright work that suits your needs or simply don't use the work at all. Second, reproduce the work, perhaps relaying on exceptions to copyright, but fully aware of the risks you're taking, for example that the exception may not apply to your particular use. What exactly are those risks? And are you, or your employer's organisation the kind that accepts low or medium risks of this nature or perhaps no risks?"

There are several risks you may face when using a third party owned copyright-protected work you don't have permission for, or for which you think an exception to copyright may apply.

You may face paying a copyright fee after using the copyright-protected work. In the worst case scenario, you may be subject to a lawsuit (which would more than likely be settled out of court).

You may face public embarrassment by the fact that you used copyright-protected materials without permission. This may be reputationally damaging, especially for a publicly-funded organisation or an organisation that either creates, licenses or distributes copyright-protected works or other intellectual property in its own right.

You may need to stop using the non-cleared work. This may encompass actions such as removing an image from your website, or editing and then re-issuing the publication that previously included the work.
The current copyright system is too heavily skewed in favour of copyright owners 


\subsection{Risk assessment}

To assess your risk of using non-cleared materials, consider the following:

The origin of the work(s)

Is the author well known? This may be riskier. Does the author or copyright holder have a reputation for strictly guarding uses of their works and/or aggressively pursuing or threatening infringers? Is the copyright owner likely to pursue legal action or to negotiate a copyright fee? Is the copyright owner likely to proceed through a trial if they commence an action?

\section{Who will have access to the work(s)}

If it's being reproduced on the web, then it's accessible to a huge number of people around the world. That increases both the risk that the copyright owner will find out, and the level of damages they might demand.

\section{Analyse your budget}

Are you prepared to pay damages, royalty payments, settlements out of court, court-related fees, and infringement-related legal advice?

\section{The "political" consequences of using materials without permission}

Would bad publicity mean less public funding? What would be the message to the public about your respect for copyright law? Would it harm your organisation in any non-monetary manner, such as reputation?

\section{Insurance}

Do you have insurance coverage for copyright infringement? Would this use be covered by the policy? How would this affect your future insurance cover and/or premiums?

\section{Emotional costs}

What are the emotional costs of a claim against you for copyright infringement? How would this affect you, any employees and your governing body (if there is one)?

\section{Inconvenience costs}

Weigh the time and inconvenience of dealing with an infringement action against the time and effort involved, as well as advantages, of using authorised materials.

\subsection{Alternatives and advice}

Before using non-cleared work, consider all possible alternatives to using the work without permission. Are there similar works you could use with permission? Are there works in the public domain or subject to Creative Commons licences? Could you or an employee create a new work to fill the gap? (On the latter idea, bear in mind that a brand new creation that is very similar to the original you are copying is likely to be considered infringing).

There are also things you can do to lessen your risk of copyright infringement, including:

- Implement a written procedure on obtaining copyright permissions, and make sure the procedure is consistently used throughout your enterprise.

- Educate your staff and end users of content about any potentially applicable copyright exceptions. Make staff aware of the penalties for violating copyright

- Conduct periodic copyright compliance spot checks in your organisation.

- Track developments related to your country's copyright statutes, international developments, court cases interpreting the law, as well as any public policies and procedures implemented at similar organisations.

- Develop a written copyright policy and keep it regularly updated. Include permission guidelines and guidelines on exceptions. Make your policy and guidelines available to all in your enterprise.

With the above advice as background, this simple equation that I have developed might help to judge whether to copy or not:

$$
R=A \times B \times C \times D
$$

$A$ is an estimate of the chances that what is being done is infringement and is not covered by an exception to copyright. $A$ can be anywhere between 0 (zero risk) and 1 (certainly infringement).

$B$ is an estimate of what the chances are that a copyright owner will find out about the possible infringement. Again, it is an estimate, and again it can range between 0 (no chance) and 1 (certainly). It would be low if the copying were shown to a restricted number of people, high if it was published in a popular magazine or was placed on the Internet.

$\mathrm{C}$ is an estimate of what are the chances that, having found out, the copyright owner chooses to sue? Again, this figure will range from 0 to 1 . By multiplying these three figures together, an estimate of the risk involved can be established. Of 
course, if an owner does complain, one should not ignore the complaint, but engage with the complainant. In the vast majority of cases, an apology will satisfy the complainant.

Finally, $D$ is the likely maximum damages and legal costs. $R$ then is the financial risk. If $R$ seems worryingly high, either get explicit permission to reproduce, or don't use the item.

Finally, remember these three points:

1. Just because you own an item does not automatically give you the right to reproduce it.

2. In most cases, the risk involved in copying and reproducing materials is low, but there are some high-risk scenarios to be aware of.

3. Use the advice and risk equation, and take sensible precautions.

\section{Notes}

1. Another general overview of copyright law can be found at https://en.wikipedia.org/wiki/Copyright

2. It turns out that the Infopaq case was not about particular words, but about the principle. The Court decided that, in principle, a string of 11 words could be a copyright work, rather than stating a specific set of 11 words was. This explains why nobody has ever reported what the words were.

3. The UK Copyright Act is particularly obscure on this matter, but section 170(2) of the Copyright Designs and Patents Act 1988 (as amended) refers.

http://www.legis/ation.gov.uk/ukpga/1988/48/section/170

4. It changes its URL from time to time; at the time this article was written it could be found at: https://sci-hub.tw

5. There are precedents for such new rights outside copyright, such as the EU's database right discussed above.

6. Section 9(3) of the UK Copyright Act.

http://www.legislation.gov.uk/ukpga/1988/48/contents

\section{References}

Brennan, David J. (2015). "The root of title to copyright in works". Intellectual property quarterly, v. 4, pp. $289-327$. http://ssrn.com/abstract=2689346

Burt, Roger; Davies, Colin (2018). "Software: intellectual property and artificial intelligence". In: Brown, Abbe E. L.; Waelde, Charlotte. Research handbook on intellectual property and creative industries. Edward Elgar, pp. 241-252. ISBN: 9781786431165

Dukes, Mark C.; Killen, Craig N. (1994). "Protection of works of authors: an overview of copyright principles". South Carolina lawyer, July/August, v. 28.

Feather, John (1994). Publishing, piracy and politics: An historical study of copyright in Britain. Mansell, p. 74. ISBN: 978 0720121353

Guadamuz, Andrés (2017). "Do androids dream of electric copyright? Comparative analysis of originality in artificial intelligence generated works". Intellectual property quarterly, n. 2. pp. 169-186.

http://sro.sussex.ac.uk/id/eprint/66693

Horváth, Katalin (2019). Al and data mining - questions of copyright.

https://cms.law/en/GBR/Publication/Al-and-data-mining-questions-of-copyright

Mazzone, Jason (2011). Copyfraud and other abuses of intellectual property law. Stanford Law Books. ISBN: 9780 804760065

Rosati, Eleonora (2011). "Originality in a work, or a work of originality: the effects of the Infopaq decision". European intellectual property review, v. 33, n. 12, pp. 746-755.

Journal of the Copyright Society of the USA, v. 58, n. 4, pp. 795-817.

Seville, Catherine (2006). The internationalisation of copyright law. Cambridge University Press. ISBN: 9780511495274 https://doi.org/10.1017/CBO9780511495274 